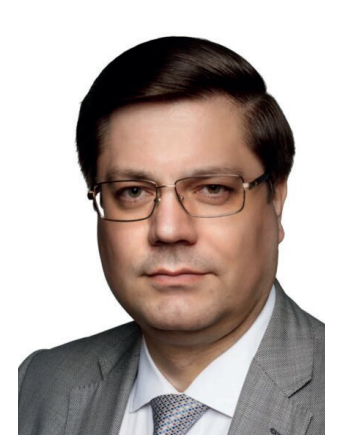

АНДРЕЙ

ВЛАДИМИРОВИЧ ГАБОВ

главный научный сотрудник Института государства и права Российской академии наук, научный руководитель юридического института Белгородского государственного национального исследовательского университета, научный руководитель юридического фракультета Ульяновского государственного университета, членкорреспондент РАН, доктор юридических наук, заслуженный юрист РФ

\section{ПЕРЕХОД ПРАВ УЧРЕДИТЕЛЯ АВТОНОМНОЙ НЕКОММЕРЧЕСКОЙ ОРГАНИЗАЦИИ}

Пандемия обострила и сделала актуальными множество проблем, которые в более спокойные времена не привлекали пристального внимания. Одна из них - переход прав учредителей некоторых унитарных некоммерческих организаций. В нотариальной практике стали возникать вопросы о возможности наследования прав и обязанностей учредителей автономных некоммерческих организаций: нотариусы исходят в таких случаях из невозможности наследования. Тем самым не только нарушаются права и обязанности наследников, но и ставится под угрозу существование таких организаций. Автор статьи показывает, что подобный подход противоречит действующему законодательству; при этом со всей очевидностью требуется довольно серьезная работа по модификации правового положения автономной некоммерческой организации.

Ключевые слова: юридическое лицо, корпорация, унитарная организация, автономная некоммерческая организация, учредитель, оборотоспособность, наследование, переход права

1. Автономная некоммерческая организация (далее - АНО) - это одна из организационно-правовых форм юридического лица, в которой создаются некоммерческие организации.

Как самостоятельная организационно-правовая форма юридического лица АНО появилась в 1996 г., когда был принят Федеральный закон от 12.01.1996 
№ 7-Ф3 «О некоммерческих организациях» (далее - Закон о некоммерческих организациях), в котором специфике правового положения АНО была посвящена отдельная ст. 10; кроме того, были отдельные упоминания АНО в ряде иных статей (ст. 14 в части учредительных документов, ст. 17 в части преобразования, ст. 29 в части органов управления). Таким образом, объем регулирования был сравнительно небольшим; основной упор в нем делался на учредительные документы АНО, в которых учредители (соучредительство здесь не запрещалось) могли регламентировать все ключевые вопросы.

Цели введения АНО изначально были не в полной мере ясны. Некоторые авторы отмечали тем не менее, что АНО могут быть квалифицированы как одна из «приоритетных форм для негосударственных некоммерческих организаций образования, культуры, искусства, здравоохранения, социальной помощи, для исследовательских центров и других организаций гуманитарной направленности». В обоснование такого взгляда указывалось на совмещение в этой форме возможности осуществлять общеполезную деятельность и «выполнять финансово-хозяйственную деятельность, привлекать средства спонсоров и инвесторов, использовать кредиты, получать субсидии, субвенции, гранты на конкретные социальные проекты при сохранении гарантированной государственной поддержки в виде льготного налогообложения» ${ }^{1}$.

Лаконичность законодательных положений об АНО и в целом отсутствие четкой системы некоммерческих юридических лиц² на определенном этапе (середина 2000-х гг.) позволили ряду исследователей говорить о ненужности АНО как самостоятельной организационно-правовой формы. Соответствующие идеи были озвучены и при обсуждении концептуальных подходов к реформам гражданского

1 См.: Краснопольская Е.А. Гражданско-правовое регулирование деятельности автономной некоммерческой организации: автореф. дис. ... канд. юрид. наук. М., 2006. C. 3 .

2 Подробнее о проблемах системы некоммерческих юридических лиц в дореформенный период см.: Габов A.B. Некоммерческие организации: теоретические и практические проблемы // Законы России: опыт, анализ, практика. 2008. № 10. С. 92-110. законодательства. Была высказана мысль о необходимости упразднить АНО в силу незначительности ее отличий от фонда ${ }^{3}$. Однако в результате реформирования законодательства о юридических лицах ${ }^{4}$ AHO мало того что сохранилась как самостоятельный вид юридического лица, но также регулирующие ее положения были перенесены в Гражданский кодекс (ГК) РФ (ст. 50, 123.24-123.25) ${ }^{5}$. Соответствующие положения Кодекса вместе с нормами Закона о некоммерческих организациях и составляют основы правового положения АНО в настоящее время.

Несмотря на указанные изменения объема и содержания законодательного регулирования $\mathrm{AHO}$, говорить о его определенности нельзя. Это касается множества вопросов ${ }^{6}$, среди которых и вопрос (не просто важный, а один из базовых, на наш взгляд) о возможности перехода прав учредителя AHO.

2. Этот вопрос в первоначальной редакции Закона о некоммерческих организациях никак не регулировался. Общие положения гражданского законодательства о юридических лицах его тоже не регулировали, по существу, оставляя его решение на усмотрение самих участников, а также государственного регистрирующего органа. Реформа зако-

${ }^{3}$ См.: Концепция развития гражданского законодательства Российской Федерации (одобрена решением Совета при Президенте РФ по кодификации и совершенствованию гражданского законодательства от 07.10.2009).

${ }_{4}^{4}$ См.: Федеральный закон от 05.05.2014 № 99-ФЗ «О внесении изменений в главу 4 части первой Гражданского кодекса Российской Федерации и о признании утратившими силу отдельных положений законодательных актов Российской Федерации».

5 Комментируя послереформенное положение АНО, Е.А. Суханов пишет, что «ранее существование АНО как особого вида юридических лиц вызывало сомнения в своей обоснованности, ибо из сравнения содержания п. 1 ст. 7 и п. 1 ст. 10 Федерального закона „О некоммерческих организациях“ вытекала полная идентичность их гражданско-правового статуса и статуса фондов. Теперь эта несуразность устранена, а существование АНО как самостоятельного вида юридических лиц стало вполне оправданным» (Суханов E.A. Комментарий к ст. 65.165.3 ГК РФ // Вестник гражданского права. 2014. № 3. C. 107-130).

6 K примеру, по вопросу о реорганизации АНО см.: Габов A.B. Реорганизация автономной некоммерческой организации // Вестник МГЛУ. Образование и педагогические науки. 2020. № 2. С. 219-239. 
нодательства о юридических лицах 2014 г. также не решила указанный вопрос.

Впервые возможность перехода прав учредителя АНО была упомянута в изменениях в ст. 15 Закона о некоммерческих организациях, внесенных в 2016 г. ${ }^{7}$ В частности, среди прочего была признана допустимой передача прав учредителя некоммерческой организации, в том числе и $\mathrm{AHO}^{8}$, иному лицу в том случае, если из АНО хочет выйти ее единственный учредитель.

Пояснительная записка к проекту соответствующего закона ${ }^{9}$ никаких указаний на цель этих изменений не содержит ${ }^{10}$. Тем не менее можно предположить, что автор рассматриваемой поправки стремился к созданию гибкого механизма изменения состава учредителей АНО, когда, с одной стороны, по понятным причинам запрещен выход единственного учредителя, а с другой - прямо предусмотрен инструмент для создания правовой возможности дальнейшего существования АНО, прекращение которого может иметь негативные последствия: передача прав учредителя иному лицу. Любопытно, что данные изменения не детализируют характер такой передачи - возмездный (когда есть какое-либо встречное предоставление) или безвозмездный, оставляя этот вопрос на усмотрение самих участников правоотношений.

7 Федеральным законом от 31.01.2016 № 7-Ф3 «О внесении изменений в отдельные законодательные акты Российской Федерации» (далее - Федеральный закон от 31.01.2016 № 7-ФЗ).

8 Эта норма в части указания на ограниченный круг некоммерческих организаций подверглась справедливой критике (см.: Дерюгина T.В. Языковые средства введения в заблуждение, или Мнимые дозволения в конструкциях гражданско-правовых договоров // Гражданское право. 2020. № 6. С. 3-7).

9 Проекту Федерального закона № 766233-6 «О внесении изменений в часть первую Гражданского кодекса Российской Федерации в части деятельности юридических лиц, а также в отдельные законодательные акты Российской Федерации» (который впоследствии стал Федеральным законом от 31.01.2016 № 7-Ф3 (см.: https://sozd.duma.gov.ru/bill/766233-6 (дата обращения: 06.09.2021)).

${ }^{10}$ Согласно Таблице поправок, рекомендуемых Комитетом по гражданскому, уголовному, арбитражному и процессуальному законодательству к принятию; автором соответствующих поправок является депутат П.В. Крашенинников (см.: https://sozd.duma.gov.ru/bill/766233-6 (дата обращения: 06.09.2021)).
Это, казалось бы, техническое решение между тем можно сравнить с открытием ящика Пандоры: впервые было признано на законодательном уровне, что права учредителя АНО могут быть предметом сделки и переходить от одного лица к другому, т.е. являются оборотоспособными.

Отметим, что в отдельных работах, вышедших до появления соответствующих законодательных решений, высказывалась мысль о невозможности изменений состава учредителей АНО, а значит, и о невозможности перехода прав учредителя АНО. K примеру, С.Д. Могилевский после анализа понятий «член», «учредитель», «участник» пришел к выводу о том, что «круг учредителей фрормируется при учреждении автономной некоммерческой организации и в дальнейшем не может быть ни расширен, ни сокращен» ${ }^{11}$. Д.В. Новак позднее, соглашаясь с таким подходом, отмечал, что он основан на «признаке отсутствия членства» у $\mathrm{AHO}^{12}$. С нашей точки зрения, как показывает анализ работ обоих авторов, никаких догматических или иных аргументов для подобного рода выводов в них в реальности не приведено. Нельзя не отметить, что в литературе встречается (Ю.П. Свит) и иная позиция - о возможности изменений состава учредителей АНО - на том основании, что «отсутствие членства не означает полного отсутствия взаимосвязи между учредителем и созданной с его участием организацией» ${ }^{13}$.

Казалось бы, принятие Федерального закона от 31.01.2016 № 7-ФЗ должно было обусловить прекращение этой дискуссии (как минимум с точки зрения практической юриспруденции), открыть возможности для легальных изменений состава учредителей $\mathrm{AHO}$ и, напротив, сделать невозможным ограничение реализации юридических фрактов, влекущих такие изменения.

${ }^{11}$ Могилевский С.Д. Автономная некоммерческая организация: правовые аспекты // Приложение к журналу «Хозяйство и право». 2006. № 10. С. 21.

${ }^{12}$ Новак Д.В. К упорядочению системы некоммерческих организаций // Вестник гражданского права. 2007. № 3. С. 8788.

${ }^{13}$ См.: Юридические лица в гражданском праве: юридические лица в российском гражданском праве (коммерческие и некоммерческие организации) / отв. ред. В.Н. Литовкин, О.В. Гутников. М., 2011. С. 938. 
Однако, к сожалению, предложенное в Законе правовое решение то ли не было оценено (или правильно расценено) в юридической практике, то ли было воспринято как частный и экстраординарный случай, но в период пандемии коронавирусной инфекции стали возникать случаи (и неоднократные в разных регионах России) отказа нотариусов в выдаче свидетельства о праве на наследство на права и обязанности учредителей $\mathrm{AHO}^{14}$.

Рассмотрим аргументы таких отказов, которые выдвигают нотариусы. Их можно свести к следующим:

1) унитарный характер АНО. Говоря по-другому, AHO - не корпорация, прав участия у учредителя нет, потому и передавать нечего ${ }^{15}$. В одном из ответов нотариусов, который изучал автор настоящей работы, вывод был следующим: «...таким образом, с позиций права юридических лиц наследодателю не принадлежат права и обязанности, в частности, корпоративные права, которые могли бы быть предметом наследования, как это указано в п. 1 ст. 1112 ГК РФ»;

2) (этот аргумент вытекает прямо из первого, но может рассматриваться как самостоятельный довод) отсутствие у учредителя АНО прав на имущество, переданное в собственность АНО;

3) неразрывность связи прав и обязанностей с личностью наследодателя.

В комментариях к подобного рода ситуациям можно встретить еще один аргумент против оборотоспособности комплекса прав учредителя АНО: некоммерческий характер этой организации. К примеру, М. Доровская безапелляционно пишет: «...поскольку организация является некоммерческой, права участия в организации (с возможностью фоормирования

\footnotetext{
${ }^{14}$ Некоторые из таких случаев обсуждались публично: Доровская М. Судьба автономной некоммерческой организации после смерти единственного учредителя и руководителя // Закон.ру. 2021. 29 июля. URL: https://zakon.ru/ blog/2021/07/29/sudba_avtonomnoj_nekommercheskoj_organizacii_posle_smerti_edinstvennogo_uchreditelya_i_rukovoditelya (дата обращения: 06.09.2021).

${ }^{15}$ Как видно, этот аргумент перекликается с ранее приведенными точками зрения С.Д. Могилевского и Д.В. Новака.
}

в дальнейшем новых органов) не передаются по наследству ${ }^{16}$.

3. С нашей точки зрения, ни один из указанных аргументов не является убедительным. Рассмотрим их подробнее.

Унитарный характер АНО. Этот аргумент не имеет под собой никаких оснований в гражданском законодательстве.

Анализ положений об унитарных организациях приводит к однозначному выводу о том, что формально в настоящее время законодатель не связывает наличие унитарного статуса юридического лица с вопросами оборотоспособности комплекса прав учредителей таких организаций. Более того, в некоторых случаях законодательство прямо указывает на возможность передачи части (или всех) прав учредителя.

Помимо указанного примера со ст. 15 Закона о некоммерческих организациях в части АНО, можно привести примеры с учреждениями, передача фрункций и полномочий учредителей которых давно является привычным делом:

- ст. 26.3 Федерального закона от 06.10.1999 № 184-Ф3 «Об общих принципах организации законодательных (представительных) и исполнительных органов государственной власти субъектов Российской Федерации» указывает, что Правительство вправе передавать в пользование либо в собственность субъектов Российской Федерации с соблюдением определенных условий федеральное имущество, а также функции и полномочия учредителя фредеральных государственных учреждений, необходимые для осуществления переданных полномочий;

- ст. 8 Федерального закона от 22.12.2020 № 437-Ф3 “О федеральной территории „Сириус“” указывает, что Правительство вправе передавать фредеральной территории «Сириус» фуннкции и полномочия учредителя федеральных государственных учреждений, необходимые для осуществления переданных полномочий.

\footnotetext{
${ }^{16}$ См.: Доровская М. Указ. соч.
} 
В названных случаях речь не идет о передаче всех функций и полномочий (хотя это и не исключено), но есть и более чистые примеры: ст. 154 Федерального закона от 22.08.2004 № 122-Ф3 прямо предусматривает возможность передачи учреждений («перечни передаваемых... государственных или муниципальных учреждений, право собственности на которые переходит к другому собственнику государственного или муниципального имущества...» и другие фррагменты).

Своеобразную фрорму перехода прав учредителя содержит Федеральный закон от 14.11.2002 № 161-Ф3 "О государственных и муниципальных унитарных предприятиях»: здесь права учредителя следуют судьбе имущества - согласно ст. 29 признается такой институт, как изменение правового положения унитарного предприятия вследствие перехода права собственности на его имущество к другому собственнику государственного или муниципального имущества (Российской Федерации, субъекту Российской Федерации или муниципальному образованию). Такая передача влечет изменение устава и считается состоявшейся с момента государственной регистрации внесенных в устав унитарного предприятия изменений.

Говоря иначе, в различной форме законодательство признает возможность изменения первоначального состава учредителей отдельных унитарных организаций. Это может быть и изменение собственности, и передача части (всех) функций и полномочий учредителя иному лицу.

Но дело не только в фрормальных примерах, включая непосредственно затрагивающий анализируемую ситуацию с АНО (ст. 15 Закона о некоммерческих организациях), и не только в отсутствии прямого законодательного запрета (и даже ограничений какого-либо рода) на переход прав учредителя унитарной организации. Поставим вопрос иначе: какие цели (интересы) могли бы лежать в основе запрета на передачу прав учредителя унитарной организации? Есть ли хоть какие-то догматические основания для подобного правового решения?

Нам представляется, что таких оснований нет.

Во-первых, закрепление неизменности состава учредителей унитарной организации - крайне неудобное решение для участников гражданских правоотношений. K примеру, лицо может утратить интерес в осуществлении функций учредителя в отношении такой организации, деятельность которой имеет большое общественное значение. И что же, теперь из-за этой утраты интереса надо проходить процедуру ликвидации и вновь создавать новую организацию на базе имущества старой? Это явно нерациональное и экономически необоснованное решение. Задача же права, как думается, иная: создать механизм изменения персонального состава учредителей, который позволял бы при утрате интереса учредителя или прекращении его правосубъектности переводить соответствующие права и обязанности на иных лиц.

Во-вторых, делать выводы о связи унитарного характера организации с невозможностью оборота прав учредителя нельзя и в силу того, что в нашем праве (и не только в текущем законодательстве) отсутствует сама концепция унитарности применительно к юридическому лицу. Что значит назвать юридическое лицо «унитарным»? Вопрос этот не имеет не то что ясного, а вообще никакого ответа. В этой части законодательства мы видим удивительное невнимание законодателя к общим вопросам правового положения унитарной организации. K примеру, если в отношении прав и обязанностей членов (участников) любых корпораций выделена отдельная ст. 65.2 ГК РФ, то в отношении унитарных организаций такого перечня нет.

Буквально (грамматически) «унитарный» - это единый, объединенный, составляющий одно целое. Применительно к существующей классификации юридических лиц в нашем праве это означает не разделенный на части, принадлежащие различным лицам. Значит, можно сделать два предположения:

- в учредителях такой организации не может быть нескольких лиц; и/или

- права (любые - на имущество, на принятие управленческих решений и т.п.) в отношении унитарной организации не могут принадлежать разным лицам.

Оба эти предположения неверны. Наше позитивное право допускает соучредительство для 
некоторых унитарных организаций (фонды, АНО), а равно принятие в отношении унитарной организации управленческих решений разными лицами (пример - разделение функций и полномочий учредителя государственного или муниципального учреждения между разными органами управления и/или лицами).

Логика отдельных нотариусов - «унитарность = необоротоспособность прав учредителя» - прямо приводит их к мысли о том, что речь могла бы идти о наследовании, если бы организация была корпоративная. То есть, выходит, корпорация в отечественном праве тем и отличается от унитарной организации, что имеет доли участия, которые могут быть унаследованы. Но эта логика также не находит подтверждения в российском праве. Наш собственный анализ различных моделей обособления имущества корпораций, используемых в российском праве, показал, что признание организации корпорацией совершенно не означает, что у учредителя (участника) возникают какие-либо права на отчуждение доли участия. В одной из прежних работ мы выделили следующие модели обособления имущества между учредителем и корпорацией:

- учредитель корпоративной организации не приобретает прав на отчуждение своих членских прав участия в организации (ст. 123.6 ГК РФ в части общественной организации); не сохраняет (не приобретает) имущественные права на имущество, переданное в собственность организации (ст. 123.4 ГК РФ в части общественных организаций). Следовательно, учредитель ни в какой форме и ни в каких случаях не сможет впоследствии получить от организации (даже при ликвидации) имущество, внесенное им при учреждении;

- учредитель корпоративной организации получает право на отчуждение своей доли в организации, а также приобретает право получить часть имущества впоследствии при ликвидации организации (акционерные общества);

- учредитель корпоративной организации вдобавок к правам, указанным во второй модели, также приобретает право получить часть имущества организации при выходе из нее (полные товарищества, комман- дитные товарищества, общества с ограниченной ответственностью, кооперативы ${ }^{17}$.

Любопытно и следующее: из положений ГК РФ, если внимательно анализировать содержание ст. 65.1 в части определения корпорации и ст. 65.2 в части общей для всех участников корпорации совокупности прав, можно сделать два вывода:

- ГК РФ не связывает корпоративный характер организации с возможностью оборота долей (прав) участия;

- ГК РФ не указывает возможность отчуждения доли участия в корпорации в качестве права участника корпорации.

Таким образом, вывод о том, что оборот прав учредителя АНО ограничен потому, что АНО не корпорация, не имеет никакого подтверждения в нашем праве.

Отсутствие у учредителя АНО прав на имущество, переданное в собственность АНО. Эта конструкция закреплена в ст. 123.24 ГК РФ:

- имущество, переданное АНО ее учредителями, является собственностью автономной некоммерческой организации;

- учредители АНО не сохраняют права на имущество, переданное ими в собственность этой организации.

Данное правило фрормально означает, что, к примеру, в отличие от приведенных выше моделей отчуждения имущества учредителями хозяйственных обществ, когда в обмен на утрату ими прав собственности они получают иные права (права участия), учредители АНО никаких иных прав при отчуждении имущества не получают.

Однако, как видно, такая утрата не помешала разработчикам Федерального закона от 31.01.2016

\footnotetext{
${ }^{17}$ См.: Корпоративное право: учеб. курс в 2 т. / отв. ред. И.С. Шиткина. Т. 1. М., 2017. С. 585-586 (автор соответствующей главы - А.В. Габов).
} 
№ 7-Ф3 ввести положения о возможности передачи прав учредителя $\mathrm{AHO}$ от одного лица к другому.

Как думается, это решение вполне допустимо.

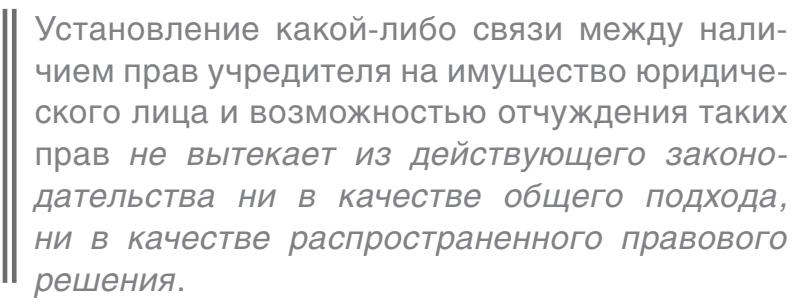

Дело в том, что отчуждению подлежат не права на имущество, а совокупность прав учредителя. При этом надо отметить, что соответствующая совокупность прав также имеет имущественный характер, поскольку она связана с управлением юридическим лицом ${ }^{18}$.

Неразрывность связи прав и обязанностей учредителя АНО с личностью учредителя. Такой аргумент, на наш взгляд, исходя из вышесказанного, не имеет права на существование.

Если бы права учредителя АНО были неразрывно связаны с его личностью, то логичными законодательными решениями были бы:

— запрет соучредительства при создании АНО; и/или

- запрет изменения состава учредителей в процессе существования $\mathrm{AHO}$;

- прямой и явный запрет отчуждения комплекса прав учредителя АНО.

Действующее законодательство исходит из прямо противоположных подходов (ст. 123.24 ГК РФ, ст. 10, 15 Закона о некоммерческих организациях):

\footnotetext{
${ }^{18}$ Имущественный характер прав учредителя АНО отмечается и в отдельных судебных актах. К примеру, в решении Ленинского районного суда г. Екатеринбурга от 29.06.2021 по делу №2-2918/2021 прямо указано: «...права и обязанности учредителя автономной некоммерческой организации носят имущественный характер, в связи с чем способны к переходу от одного лица к другому, в отсутствие законодательного запрета, такие права являются объектом наследственного преемства».
}

— возможность соучредительства в АНО;

- возможность выхода учредителя из состава АНО и приема в ее состав иных учредителей;

- возможность перехода прав учредителя АНО к иным лицам.

При анализе этого аргумента надо обратить внимание и на то, что составляет основу комплекса прав учредителя $\mathrm{AHO}$, - право на управление деятельностью АНО (ст. 123.25 ГК РФ). В конечном итоге такое право заключается в возможности принимать решения в отношении имущества юридического лица как прямо, так и опосредованно, а потому говорить о том, что соответствующие права носят личный неимущественный характер, нельзя ${ }^{19}$.

Некоммерческий характер $\mathrm{AHO}^{20}$. Частично здесь можно воспроизвести ряд аргументов, высказанных выше, относительно попыток обусловить невозможность отчуждения комплекса прав учредителя АНО унитарным характером АНО: действующее законодательство не связывает наличие у юридического лица статуса некоммерческого с возможностью/ невозможностью отчуждения прав учредителя.

Более того, законодательство дает примеры совершенно противоположные: потребительские кооперативы, паи в которых могут передаваться иным лицам (см. ст. 16 Федерального закона от 08.12.1995 № 193-Ф3 “О сельскохозяйственной кооперации»), а также наследоваться (ст. 1177 ГК РФ и нормы специальных законов).

В качестве контраргумента можно возразить, что потребительские кооперативы - это своего рода частный случай, исторически сложившийся подход. Однако заметим, что иной подход - ограничение отчуждения прав учредителя в некоммерческих орга-

${ }^{19}$ Ранее мы проводили соответствующий анализ применительно к содержанию ценных бумаг (см.: Габов А.B. Неимущественные элементы в содержании ценной бумаги // Адвокат. 2009. № 4. С. 18-30).

${ }^{20}$ Как показывает анализ исследований, попытки связать некоммерческий характер организации с невозможностью наследования прав ее учредителя встречаются не только в отношении АНО (см., напр.: Клещев C.Е. Наследование имущества частных учреждений // Наследственное право. 2013. № 3. C. 36-39). 
низациях - с догматической точки зрения не находит никакого разумного объяснения. Сама возможность отчуждения таких прав - это не обход некоммерческого статуса, а лишь удобный правовой инструмент для непрерывности существования юридического лица.

\section{4. Подводя итоги, отметим следующее.}

Совершенно очевидно, что вопрос о наследовании прав учредителя АНО должен решаться в пользу его допустимости и возможности.

Права и обязанности учредителя АНО не запрещены к отчуждению, они могут переходить к иным лицам по воле учредителя (ст. 15 Закона о некоммерческих организациях), тем более могут они и наследоваться исходя из ст. 1112 ГК РФ (как по завещанию, так и по закону).

Ситуация, сложившаяся с наследованием прав учредителя $\mathrm{AHO}$, заставляет вновь обратить пристальное внимание на состояние отечественного законодательства о юридических лицах. К сожалению, реформы 2014 г. не только не навели сколь-нибудь приемлемый порядок в этой части законодательства, но и, напротив, привели как к обострению прежних проблем, так и к появлению новых. С разделением всех юридических лиц на корпорации и унитарные организации связывали весьма большие ожидания ${ }^{21}$; не меньше ожиданий было от предстоящего наведения порядка с разделением юридических лиц на коммерческие и некоммерческие. Однако пока эти ожидания себя на оправдали.

Учитывая то, как тяжело шла реформа юридических лиц и к каким (иногда противоположным) результатам она привела, надеяться на проведение в ближайшие годы тотальной ревизии законодательства о юридических лицах не приходится.

Видимо, путь, который нас ждет, - это точечные ситуативные изменения по наиболее острым вопросам. И для обеспечения публичных интересов (создания

${ }^{21}$ См., напр.: Серова О.А. Теоретико-методологические и практические проблемы классификации юридических лиц современного гражданского права России: монография. M., 2011. C. 138. надежной правовой основы для непрерывного существования некоммерческих организаций, нередко выполняющих общественно значимые функции), и для защиты прав наследников назрели изменения в гражданское законодательство, регулирующее вопросы наследования прав учредителей некоммерческих организаций в целом и АНО в частности, а также вопросы перехода прав учредителей некоммерческих и/или унитарных организаций в целом.

\section{Turnover of the Set of Rights of the Founder of an Autonomous Non-Profit Organisation}

The pandemic has exacerbated and made relevant many issues that in quieter times did not attract much attention. One of such issues was the legal regime of the complex of rights and obligations of the founders of some unitary organisations. In particular, in notarial practice, in connection with the death of the founders of autonomous non-profit organisations, questions began to arise about the possibility of inheriting the rights and obligations of the founders of such organisations. The current legislation has not previously spoiled the participants of civil turnover with the certainty of the norms on the legal status of autonomous nonprofit organisations. During the pandemic, it became clear that the regulation is so vague that it generates numerous disputes related to the approach of notaries who believe that the rights and obligations of the founder of an autonomous non-profit organisation cannot be the subject of inheritance. This not only violates the rights and obligations of heirs, but also threatens the existence of such organisations. The author of the article shows that this approach is not based on the norms of the current legislation; at the same time, quite serious work is obviously required to modify the legal status of an autonomous non-profit organisation.

Keywords: legal entity, corporation, unitary organisation, autonomous non-profit organisation, founder, turnover, inheritance, transfer of rights

\section{INFORMATION ABOUT THE AUTHOR}

\section{Andrey V. Gabov}

Chief Researcher at the Institute of State and Law of the Russian Academy of Sciences, Scientific Director of the Institute of Law at Belgorod State National Research University, Scientific Director of the Faculty of Law at Ulyanovsk State University, Correspond- 
ing Member of RAS, Doctor of Juridical Sciences, Honoured Lawyer of the Russian Federation (e-mail: gabov@igpran.ru).

\section{REFERENCES}

Deryugina, T.V. "Linguistic Means of Misrepresentation or Fictitious Permissions in Structures of Civil Law Contracts" [Yazykovyye sredstva vvedeniya v zabluzhdeniye, ili Mnimyye dozvoleniya v konstruktsiyakh grazhdansko-pravovykh dogovorov]. Civil Law [Grazhdanskoye pravo]. 2020. No. 6. P. 3-7.

Gabov, A.V. "Non-Profit Organisations: Theoretical and Practical" [Nekommercheskiye organizatsii: teoreticheskiye i prakticheskiye problemy]. Law of Russia: Experience, Analysis, Practice [Zakony Rossii: opyt, analiz, praktika]. 2008. No. 10. P. 92-110.

Gabov, A.V. "Non-Property Elements in the Content of a Security" [Neimushchestvennyye elementy $v$ soderzhanii tsennoy bumagi]. Advocate [Advokat]. 2009. No. 4. P. 18-30.

Gabov, A.V. "Reorganization of Autonomous Non-Profit Organization" [Reorganizatsiya avtonomnoy nekommercheskoy organizatsii]. Vestnik of Moscow State Linguistic University. Education and Teaching [Vestnik MGLU. Obrazovaniye i pedagogicheskiye nauki]. 2020. No. 2. P. 219-239.

Kleshchev, S.E. "Inherit the Property of Private Institutions" [Nasledovaniye imushchestva chastnykh uchrezhdeniy]. Inheritance Law [Nasledstvennoye pravo]. 2013. No. 3. P. 36-39.

Krasnopol'skaya, E.A. Civil Law Regulation of the Activities of an Autonomous Non-Profit Organisation: A Summary of a Candidate of Juridical Sciences Thesis [Grazhdansko-pravovoye regulirovaniye deyatel'nosti avtonomnoy nekommercheskoy organizatsii: avtoref. dis. na soiskanie uchenoy stepeni kand. yurid. nauk]. Moscow, 2006. 26 p.

Litovkin, V.N. and Gutnikov, O.V. (eds.). Legal Entities in Civil Law: Legal Entities in Russian Civil Law (Commercial and Non-Profit Organizations) [Yuridicheskiye litsa $v$ grazhdanskom prave: Yuridicheskiye litsa $v$ rossiyskom grazhdanskom prave (kommercheskiye i nekommercheskiye organizatsii)]. Moscow, 2011. 1024 p.

Mogilevskiy, S.D. "Autonomous Non-Profit Organization: Legal Aspects" [Avtonomnaya nekommercheskaya organizatsiya: pravovyye aspekty]. Business and Law. Appendix [Prilozheniye k zhurnalu "Khozyaystvo i pravo"]. 2006. No. 10.

Novak, D.V. "To Streamline the System of Non-Profit Organizations" [K uporyadocheniyu sistemy nekommercheskikh organizatsiy]. Civil Law Review [Vestnik grazhdanskogo prava]. 2007. No. 3. P. 61-98.

Serova, O.A. Theoretical, Methodological and Practical Problems of Classification of Legal Entities under Modern Civil Law of Russia: A Monograph [Teoretiko-metodologicheskiye i prakticheskiye problemy klassifikatsii yuridicheskikh lits sovremennogo grazhdanskogo prava Rossii: monografiya]. Moscow, 2011. 328 p.

Shitkina, I.S. (ed.). Corporate Law: A Course Book in 2 vol. [Korporativnoye pravo: ucheb. kurs v 2 t.]. Vol. 1. Moscow, 2017. $976 \mathrm{p}$.

Sukhanov, E.A. "Commentary to Art. 65.1-65.3 of the Civil Code of the Russian Federation" [Kommentariy k st. 65.1-65.3 GK RF]. Civil Law Review [Vestnik grazhdanskogo prava]. 2014. No. 3. P. 107-130. 